Pacific Journal of Mathematics

SOME THEOREMS ON THE RATIO OF EMPIRICAL
DISTRIBUTION TO THE THEORETICAL DISTRIBUTION 


\title{
SOME THEOREMS ON THE RATIO OF EMPIRICAL DISTRIBUTION TO THE THEORETICAL DISTRIBUTION
}

\author{
S. C. TANG
}

1. Introduction. Let $X_{1}, X_{2}, \cdots, X_{n}$ be mutually independent random variables with the common cumulative distribution function $F(x)$. Let $X_{1}^{*}, X_{2}^{*}, \cdots, X_{n}^{*}$ be the same set of variables rearranged in increasing order of magnitude. In statistical language $X_{1}, X_{2}, \cdots, X_{n}$ form a sample of $n$ drawn from the distribution with distribution function $F(x)$. The empirical distribution of the sample $X_{1}, \cdots, X_{n}$ is the step function $F_{n}(x)$ defined by

$$
F_{n}(x)= \begin{cases}0 & \text { for } x \leqq X_{1}^{*} \\ \frac{k}{n} & \text { for } X_{k}^{*}<x \leqq X_{k+1}^{*} \\ 1 & \text { for } x>X_{n}^{*}\end{cases}
$$

A. Kolmogorov developed a well-known limit distribution law for the difference between the empirical distribution and the corresponding theoretical distribution, assuming $F(x)$ continuous:

$$
\lim _{n \rightarrow \infty} P\left\{\sqrt{n} \sup _{-\infty<x<\infty}\left|F_{n}(x)-F(x)\right|<z\right\}= \begin{cases}0, & \text { for } z \leqq 0, \\ \sum_{k=-\infty}^{\infty}(-1)^{k} e^{-2 k^{2} x^{2}}, & \text { for } z>0 .\end{cases}
$$

Equally interesting is Smirnov's theorem:

$$
\lim _{n \rightarrow \infty} P\left\{\sqrt{n} \sup _{-\infty<x<\infty}\left[F_{n}(x)-F(x)\right]<z\right\}= \begin{cases}0, & \text { for } z \leqq 0 \\ 1-e^{-2 z^{2}}, & \text { for } z>0 .\end{cases}
$$

In this paper we shall study the ratio of the empirical distribution to the theoretical distribution, and evaluate the distribution functions of the upper and lower bounds of the ratio. We shall prove the following four theorems.

THeOREM 1. If $F$ is everywhere continuous then

$$
P\left\{\sup _{0 \leqq F(x) \leqq 1} \frac{F_{n}(x)}{F(x)}<z\right\}=s(z)= \begin{cases}0 & \text { for } z \leqq 1 \\ 1-\frac{1}{z} & \text { for } z>1\end{cases}
$$

Received July 28, 1961. I am deeply indebted to the referee for his corrections of my English writing. Without his aid, the present paper would not be read clearly, although the responsibility of errors rests with me. 
THEOREM 2. Let $c$ be a positive number no larger than $n$ and suppose that $F(x)$ is continuous in the range $0 \leqq F(x) \leqq c / n$. Then

$$
P\left\{\sup _{0<F(x) \leqq \frac{c}{n}} \frac{F_{n}(x)}{F(x)}<z\right\}=\left\{\begin{array}{cc}
\left(\sum_{r=0}^{[c z]}\left(\begin{array}{l}
n \\
r
\end{array}\right)^{r}\left(1-\frac{c}{n}\right)^{n-r}\left(\frac{c}{n}\right)^{r}\right. \\
-\sum_{k=1}^{[c z]}\left(\begin{array}{l}
n \\
k
\end{array}\right) \frac{k^{k-1}(n z-k)^{n-k}}{(n z)^{n}} \\
\cdot \sum_{r=k}^{[c z]}\left(\begin{array}{l}
n-k \\
r-k
\end{array}\right)\left(\frac{c z-k}{n z-k}\right)^{r-k}\left(1-\frac{c z-k}{n z-k}\right)^{n-r} \\
0 & \text { for } 0<z \leqq \frac{n}{c} \\
1-\frac{1}{z} & \text { for } z \leqq 0
\end{array}\right.
$$

THEOREM 3. Under the assumption of Theorem 1,

$$
P\left\{\inf _{0<F_{n}(x) \leqq 1} \frac{F_{n}(x)}{F(x)} \leqq z\right\}=I_{n}(z)=\left\{\begin{array}{cc}
0 & \text { for } z<\frac{1}{n} \\
\left(1-\frac{1}{n z}\right)^{n} & \text { for } \frac{1}{n} \leqq z \leqq 1 \\
+\sum_{k=1}^{n z}\left(\begin{array}{l}
n \\
k
\end{array}\right) \frac{(k-1)^{k-1}(n z-k)^{n-k}}{(n z)^{n}} & \text { for } z>1 .
\end{array}\right.
$$

THEOREM 4. Under the assumptions of Theorem 2, if $1 \leqq c \leqq n$ then

$$
P\left\{\inf _{0<F_{n}(x) \leqq \frac{c}{n}} \frac{F_{n}(x)}{F(x)} \leqq z\right\}=\left\{\begin{array}{l}
0 \quad \text { for } z<\frac{1}{n} \\
\left(1-\frac{1}{n z}\right)^{n}+\sum_{k=1}^{[n z]}\left(\begin{array}{l}
n \\
k
\end{array}\right) \frac{(k-1)^{k-1}(n z-k)^{n-k}}{(n z)^{n}} \\
\text { for } \frac{1}{n} \leqq z \leqq \frac{c}{n} \\
\left(1-\frac{1}{n z}\right)^{n}+\sum_{k=1}^{[c]}\left(\begin{array}{l}
n \\
k
\end{array}\right) \frac{(k-1)^{k-1}(n z-k)^{n-k}}{(n z)^{n}} \\
\text { for } z>\frac{c}{n} .
\end{array}\right.
$$

2. An elementary lemma. We shall use the following lemma. 
LEMMA. Let $k$ be a positive integer and $\alpha$ an arbitrary real number. Then

$$
\begin{gathered}
\sum_{r=1}^{k} \frac{r^{r-1}}{r !} \frac{(\alpha-r)^{k-r}}{(k-r) !}=\frac{\alpha^{k-1}}{(k-1) !}, \\
\frac{(\alpha-1)^{k}}{k !}+\sum_{r=1}^{k} \frac{(r-1)^{r-1}}{r !} \frac{(\alpha-r)^{k-r}}{(k-r) !}=\frac{\alpha^{k}}{k !} .
\end{gathered}
$$

If $\alpha=k$ (a special case) then

$$
\begin{gathered}
\sum_{r=1}^{k} \frac{r^{r-1}}{r !} \frac{(k-r)^{k-r}}{(k-r) !}=\frac{k^{k-1}}{(k-1) !}=\frac{k^{k}}{k !}, \\
\frac{(k-1)^{k}}{k !}+\sum_{r=1}^{k} \frac{(r-1)^{r-1}}{r !} \frac{(k-r)^{k-r}}{(k-r) !}=\frac{k^{k}}{k !} .
\end{gathered}
$$

Proof. Let $f(x)$ be a polynomial whose degree is less than $k$. Then

$$
\sum_{r=0}^{k}\left(\begin{array}{l}
k \\
r
\end{array}\right)(-1)^{r} f(r)=(-1)^{n}\left[\Delta_{n} f(x)\right]_{x=0}=0
$$

i.e.

$$
\sum_{r=1}^{k}\left(\begin{array}{l}
k \\
r
\end{array}\right)(-1)^{r} f(r)=-f(0) \text {. }
$$

Now we can directly obtain (2) and (3):

$$
\begin{aligned}
\sum_{r=1}^{k} \frac{r^{r-1}}{r !} \frac{(\alpha-\gamma)^{k-r}}{(k-r) !} & =\sum_{r=1}^{k} \frac{r^{r-1}}{r !} \sum_{s=0}^{k-r} \frac{\alpha^{s}(-r)^{k-r-s}}{s !(k-r-s) !} \\
& =\sum_{s=0}^{k-1} \frac{(-1)^{k-s} \alpha^{s}}{s !} \sum_{r=1}^{k-s} \frac{(-1)^{r} r^{k-s-1}}{r !(k-r-s) !} \\
& =\frac{(-1)^{k-(k-1)} \alpha^{k-1}}{(k-1) !}(-1)=\frac{\alpha^{k-1}}{(k-1) !} \\
\frac{(\alpha-1)^{k}}{k !}+\sum_{r=1}^{k} \frac{(r-1)^{r-1}}{r !} \frac{(\alpha-r)^{k-r}}{(k-r) !} & \frac{(\alpha-1)^{k}}{k !}+\sum_{r=1}^{k} \frac{(r-1)^{r-1}}{r !} \sum_{s=0}^{k-r} \frac{(\alpha-1)^{s}(-r+1)^{k-r-s}}{s !(k-r-s) !} \\
= & \frac{(\alpha-1)^{k}}{k !}+\sum_{s=0}^{k-1} \frac{(-1)^{k-s}(\alpha-1)^{s}}{s !} \sum_{r=1}^{k-s} \frac{(-1)^{r}(r-1)^{k-s-1}}{r !(k-r-s) !} \\
= & \frac{(\alpha-1)^{k}}{k !}+\sum_{s=0}^{k-1} \frac{(-1)^{k-s}(\alpha-1)^{s}(-1)^{k-s}}{s !(k-s) !} \\
= & \sum_{s=0}^{k} \frac{(\alpha-1)^{s}}{s !(k-s) !}=\frac{\alpha^{k}}{k !} \cdot
\end{aligned}
$$

3. Proof of Theorem 1. First we consider the case $z \geqq 1$. Let $y_{k}$ be the largest root of the equation 


$$
F(x)=\frac{k}{n z} \quad(1 \leqq k \leqq n) .
$$

Since $F$ is continuous, $y_{k}$ is well defined. Now we evaluate probability of the inequality

$$
\sup _{0 \leqq F^{\prime}(x) \leqq 1} \frac{F_{n}(x)}{F(x)} \geqq z
$$

that is, the probability that there exists an $x$ such that

$$
\frac{F_{n}(x)}{F(x)} \geqq z \text {. }
$$

If (7) is true, then, since $F(x)$ is nondecreasing and $\lim _{x \rightarrow \infty}\left(F_{n}(x) / F(x)\right)=$ 1 , there exists an $x_{0}$ such that

$$
\frac{F_{n}\left(x_{0}\right)}{F\left(x_{0}\right)}=z
$$

By the definition of $F_{n}, F_{n}\left(x_{0}\right)=k / n$ for some $k$, so that $F\left(x_{0}\right)=$ $k / n z$. Therefore we can take $x_{0}$ as one of $y_{k}$. In other words, for one value of $y_{k}$ we have

$$
F_{n}\left(y_{k}\right)=\frac{k}{n}
$$

and the inequality

$$
X_{k}^{*}<y_{k} \leqq X_{k+1}^{*}
$$

is true. Now let $A_{k}$ be the event that this inequality holds.

Clearly (6) occurs if, and only if, at least one among the events

$$
A_{1}, A_{2}, A_{3}, \cdots, A_{n}
$$

occurs. Generally the $A_{k}$ are not mutually exclusive events so that the additive law is of no use. We may, with the help of an associated set of mutually exclusive events, deal with this situation. Put

$$
u_{k}=\bar{A}_{1} \bar{A}_{2} \cdots \bar{A}_{k-1} A_{k} \quad(k=1,2, \cdots, n) .
$$

where $\bar{A}$ denotes the complementary event of $A$. We have

$$
P\left\{\sup _{0<F(x) \leqq 1} \frac{F_{n}(x)}{F(x)} \geqq z\right\}=P\left\{\sum_{k=1}^{n} A_{k}\right\}=P\left\{\sum_{k=1}^{n} u_{k}\right\}=\sum_{k=1}^{n} P\left(u_{k}\right) .
$$

If we employ the following conditional probability formula, we can evaluate $P\left(u_{k}\right)$.

$$
P\left(A_{k}\right)=\sum_{r=1}^{k} P\left(u_{r}\right) P\left\{A_{k} \mid u_{r}\right\}=\sum_{r=1}^{k} P\left(u_{r}\right) P\left\{A_{k} \mid A_{r}\right\} .
$$


Now $A_{k}$ occurs if $k$ of the $n$ observations fall to the left of $y_{k}$, and $n-k$ to the right; hence

$$
P\left(A_{k}\right)=\left(\begin{array}{l}
n \\
k
\end{array}\right)\left(\frac{k}{n z}\right)^{k}\left(1-\frac{k}{n z}\right)^{n-k} .
$$

And $P\left(A_{k} \mid A_{r}\right)$ is the probability that of $(n-r)$ observations, known to lie to the right of $y_{r},(k-r)$ lie to the left of $y_{k}$ and $n-k$ to the right. The probability of occurrence of an event, whose value is greater than or equal to $y_{r}$ and is on the interval $y_{r} \leqq x \leqq y_{k}$ is

$$
\frac{k / n z-r / n z}{1-r / n z}=\frac{k-r}{n z-r} \text {. }
$$

Therefore

$$
P\left(A_{k} \mid A_{r}\right)=\left(\begin{array}{l}
n-r \\
k-r
\end{array}\right)\left(\frac{k-r}{n z-r}\right)^{k-r}\left(1-\frac{k-r}{n z-r}\right)^{n-k} .
$$

If we employ the notation

$$
p_{k}(z)=\frac{(n z-n+k)^{k}}{k !},
$$

we get

$$
P\left(A_{k}\right)=\frac{p_{k}(1) p_{n-k}(z)}{p_{n}(z)}, \quad P\left(A_{k} \mid A_{r}\right)=\frac{p_{k-r}(1) p_{n-k}(z)}{p_{n-r}(z)} .
$$

Equation (10) can be reduced to

$$
\begin{aligned}
& \frac{p_{k}(1) p_{n-k}(z)}{p_{n}(z)}=\sum_{r=1}^{k} P\left(u_{r}\right) \frac{p_{k-r}(1) p_{n-k}(z)}{p_{n-r}(z)}, \\
& p_{k}(1)=\sum_{r=1}^{k} P\left(u_{r}\right) \frac{p_{n}(z)}{p_{n-r}(z)} p_{k-r}(1) .
\end{aligned}
$$

Hence $P_{k}(1)=k^{k} / k$ ! and $P_{k-r}(1)=(k-r)^{k-r} /(k-r)$ !. By (3) of our lemma we know that

$$
P\left(u_{r}\right) \frac{p_{n}(z)}{p_{n-r}(z)}=\frac{r^{r-1}}{r !}, \quad P\left(u_{r}\right)=\frac{r^{r-1}}{r !} \frac{p_{n-r}(z)}{p_{n}(z)}=\frac{n !}{(n z)^{n}} \frac{r^{r-1}}{r !} \frac{(n z-r)^{n-r}}{(n-r) !} .
$$

And (9) and the (2) of our lemma tell us that

$$
\begin{aligned}
P\left\{\sup _{0<F(x) \leqq 1} \frac{F_{n}(x)}{F(x)}<z\right\} & =1-P\left\{\sup _{0 \leqq F(x) \leqq 1} \frac{F_{n}(x)}{F(x)} \geqq z\right\}=1-\sum_{k=1}^{n} P\left(u_{k}\right) \\
& =1-\frac{n !}{(n z)^{n}} \sum_{k=1}^{n} \frac{k^{k-1}}{k !} \frac{(n z-k)^{n-k}}{(n-k) !} \\
& =1-\frac{n !}{(n z)^{n}} \frac{(n z)^{n-1}}{(n-1) !}=1-\frac{1}{z}, \quad(z \geqq 1) .
\end{aligned}
$$


This completes the proof of Theorem 1.

Proof of Theorem 2. Since the ratio is nonnegative, the probability of the inequality is zero if $z \leqq 0$. Under the condition $z>n / c$, we know that the event $\left\{\sup _{0<F(x) \leqq c / n} F_{n}(x) / F(x) \geqq z\right\}$ is still equal to $\sum_{k=1}^{n} A_{k}$ by the result of Theorem 1 . Suppose $0<z \leqq n / c$. Then

$$
P\left\{\sup _{0<F(x) \leqq \frac{c}{n}} \frac{F_{n}(x)}{F(x)} \geqq z\right\}=P\left\{\sum_{k=1}^{[c z]} A_{k}+A_{c z}^{*}\right\}=\sum_{k=1}^{[c z]} P\left(u_{k}\right)+P\left(u_{c z}^{*}\right),
$$

where

$$
\begin{aligned}
& A_{c z}^{*}=\left\{X_{[c z]+1}^{*}<y_{c z}\right\}, \quad y_{c z}=\sup \left\{x: F(x)=\frac{c}{n}\right\}, \\
& u_{c z}^{*}=\bar{A}_{1} \bar{A}_{2} \cdots \bar{A}_{[c z]} A_{c z}^{*} .
\end{aligned}
$$

Since $P\left(U_{k}\right)$ has been computed, we need only evaluate $P\left(U_{c z}^{*}\right)$. We have

$$
\begin{aligned}
P\left(A_{c z}^{*}\right) & =\sum_{k=1}^{[c z]} P\left(u_{k}\right) P\left\{A_{c z}^{*} \mid A_{k}\right\}+P\left(u_{c z}^{*}\right) P\left\{A_{c z}^{*} \mid A_{c z}^{*}\right\}, \\
P\left(u_{c z}^{*}\right) & =P\left(A_{c z}^{*}\right)-\sum_{k=1}^{[c z]} P\left\{A_{c z}^{*} \mid A_{k}\right\} .
\end{aligned}
$$

From this we obtain

$$
\begin{aligned}
P\left\{\sup _{0 \leqq F^{\prime}(x) \leqq \frac{c}{n}} \frac{F_{n}(x)}{F(x)}<z\right\}= & 1-\sum_{k=1}^{[c z]} P\left(u_{k}\right)-P\left(u_{c z}^{*}\right) \\
= & 1-P\left(A_{c z}^{*}\right)-\sum_{k=1}^{[c z]} P\left(u_{k}\right)\left[1-P\left\{A_{c z}^{*} \mid A_{k}\right\}\right] \\
= & P\left(\bar{A}_{c z}^{*}\right)-\sum_{k=1}^{[c z]} P\left(u_{k}\right) P\left\{\bar{A}_{c z}^{*} \mid A_{k}\right\} \\
= & \sum_{r=0}^{[c z z]}\left(\begin{array}{l}
n \\
r
\end{array}\right)\left(\frac{c}{n}\right)^{r}\left(1-\frac{c}{n}\right)^{n-r}-\sum_{k=1}^{[c z]}\left(\begin{array}{l}
n \\
k
\end{array}\right) \frac{\not k^{k-1}(n z-k)^{n-k}}{(n z)^{n}} \\
& \cdot \sum_{r=k}^{[c z]}\left(\begin{array}{l}
n-k \\
r-k
\end{array}\right)\left(\frac{c z-k}{n z-k}\right)^{r-k}\left(1-\frac{c z-k}{n z-k}\right)^{n-r} .
\end{aligned}
$$

Since

$$
\begin{aligned}
P\left(\bar{A}_{c z}^{*}\right)=P\left\{y_{c z} \leqq X_{[c z]+1}^{*}\right\} & =\sum_{r=0}^{[c z]} P\left\{X_{r}^{*}<y_{c z} \leqq X_{r+1}^{*}\right\} \\
& =\sum_{r=0}^{[c z]}\left(\begin{array}{l}
n \\
r
\end{array}\right)\left(\frac{c}{n}\right)^{r}\left(1-\frac{c}{n}\right)^{n-r}
\end{aligned}
$$

we have

$$
P\left(\bar{A}_{c z}^{*} \mid A_{k}\right)=\sum_{r=k}^{[c z]}\left(\begin{array}{c}
n-k \\
r-k
\end{array}\right)\left(\frac{c z-k}{n z-k}\right)^{r-k}\left(1-\frac{c z-k}{n z-k}\right)^{n-r}
$$


which completes the proof. The distribution of Theorem 1 is continuous; the distribution of Theorem 2 is not continuous on the interval $0 \leqq$ $z \leqq n / c$.

Theorem 3 is a special case of Theorem 4 under the condition $c=n$. In fact, by (4) of our lemma, setting $z=1$, we deduce Theorem 3 as follows:

$$
\begin{aligned}
P\left\{\inf _{0<F_{n}(x) \leqq 1} \frac{F_{n}(x)}{F(x)} \leqq 1\right\} & =\left(1-\frac{1}{n}\right)^{n}+\sum_{k=1}^{n}\left(\begin{array}{l}
n \\
k
\end{array}\right) \frac{(k-1)^{k-1}(n-k)^{n-k}}{n^{n}} \\
& =\frac{n !}{n^{n}}\left[\frac{(n-1)^{n}}{n !}+\sum_{k=1}^{n} \frac{(k-1)^{k-1}}{k !} \frac{(n-k)^{n-k}}{(n-k) !}\right] \\
& =\frac{n !}{n^{n}} \frac{n^{n}}{n !}=1 .
\end{aligned}
$$

Thus we need only prove Theorem 4. The distribution function of Theorem 3 has a discontinuity corresponding to $z=1$; the distribution function of Theorem 4 is continuous on the interval $1 \leqq c \leqq n$.

5. Proof of Theorem 4. On the internal $F_{n}(x)>0$ the maximum of $F(x)$ is 1 ; the minimum of $F_{n}(x)$ is $1 / n$. From these results it follows that the lower bound of the ratio is no smaller than $1 / n$. Therefore

$$
P\left\{\inf _{0<F_{n}(x) \leqq \frac{c}{n}} \frac{F_{n}(x)}{F(x)} \leqq z\right\}=0
$$

if $z<1 / n$. Let $z_{k}$ be the least root of the equation

$$
F(x)=\frac{k}{n z} \quad\left(z \geqq \frac{1}{n}, \quad 1 \leqq k \leqq[n z]\right) .
$$

Define events

$$
\begin{aligned}
& B_{0}: X_{1} \geqq z_{1}, \\
& B_{k}: X_{k}^{*}<z_{k} \leqq X_{k+1}^{*} .
\end{aligned}
$$

If $1 / n \leqq z \leqq c / n$, the event

$$
\inf _{0<F_{n}(x) \leqq \frac{c}{n}} \frac{F_{n}(x)}{F(x)} \leqq z
$$

is the union of the events

$$
B_{0}, B_{1}, B_{2}, \cdots, B_{[n z]} \cdot
$$

For the purpose of evaluating the probability of $\sum_{k} B_{k}$ we put

$$
V_{0}=B_{0}, \quad V_{k}=\bar{B}_{0} \bar{B}^{1} \cdots \bar{B}_{k-1} B_{k} \quad(k=1,2, \cdots,[n z]) .
$$


We have

$$
P\left(B_{k}\right)=\sum_{r=0}^{k} P\left(V_{r}\right) P\left(B_{k} \mid B_{r}\right), \quad(k=0,1, \cdots,[n z]) .
$$

Here

$$
\begin{gathered}
P\left(V_{0}\right)=P\left(B_{0}\right)=\left(1-\frac{1}{n z}\right)^{n}, \\
P\left\{B_{k} \mid B_{0}\right\}=\left(\begin{array}{l}
n \\
k
\end{array}\right)\left(\frac{k-1}{n z-1}\right)^{k}\left(\frac{n z-k}{n z-1}\right)^{n-k} .
\end{gathered}
$$

Now we transform (11) into the following form:

$$
\begin{aligned}
\frac{p_{k}(1) p_{n-k}(z)}{p_{n}(z)} & =\frac{(k-1)^{k} p_{n-k}(z)}{k ! p_{n}(z)}+\sum_{r=1}^{k} P\left(V_{r}\right) \frac{p_{k-r}(1) p_{n-k}(z)}{p_{n-r}(z)}, \\
p_{k}(1) & =\frac{(k-1)^{k}}{k !}+\sum_{r=1}^{k} P\left(V_{r}\right) \frac{p_{n}(z)}{p_{n-r}(z)} p_{k-r}(1) .
\end{aligned}
$$

By (4) of our lemma we obtain

$$
P\left(V_{r}\right)=\frac{(r-1)^{r-1}}{r !} \frac{p_{n-r}(z)}{p_{n}(z)}=\left(\begin{array}{l}
n \\
r
\end{array}\right) \frac{(r-1)^{r-1}(n z-r)^{n-r}}{(n z)^{n}},(1 \leqq r \leqq[n z]) .
$$

It follows that if $1 / n \leqq z \leqq c / n$,

$$
\begin{aligned}
P\left\{\inf _{0<F_{n}(x) \leqq \frac{c}{n}} \frac{F_{n}(x)}{F(x)} \leqq z\right\} & =P\left\{\sum_{k=0}^{[n z]} B_{k}\right\}=\sum_{k=0}^{[n z]} P\left(V_{k}\right) \\
& =\left(1-\frac{1}{n z}\right)^{n}+\sum_{k=1}^{[n z]}\left(\begin{array}{l}
n \\
k
\end{array}\right) \frac{(k-1)^{k-1}(n z-k)^{n-k}}{(n z)^{n}} .
\end{aligned}
$$

If $z>c / n$,

$$
\begin{aligned}
P\left\{\inf _{0<F_{n}(x) \leqq \frac{c}{n}} \frac{F_{n}(x)}{F(x)} \leqq z\right\} & =P\left\{\sum_{k=0}^{[c]} B_{k}\right\}=\sum_{k=0}^{[c]} P\left(V_{k}\right) \\
& =\left(1-\frac{1}{n z}\right)^{n}+\sum_{k=1}^{[c]}\left(\begin{array}{l}
n \\
k
\end{array}\right) \frac{(k-1)^{k-1}(n z-k)^{n-k}}{(n z)^{n}} .
\end{aligned}
$$

Theorem 4 is thus proved.

6. Conclusions. Theorems 1 and 3 can be applied to test whether statistical data correspond with the theoretical distribution or not. In the process of testing, $z_{s}$ and $z_{i}$ are separately representative of the ratio's upper and lower bounds. If $S\left(z_{s}\right)$ is small and $I_{n}\left(z_{i}\right)$ large, we conclude that the empirical data in two extreme tails correspond with the theoretical distribution; conversely, if $S\left(z_{s}\right)$ is very large and $I_{n}\left(z_{i}\right)$ very small, the statistical data do not correspond with the theoretical distribution. Our test is more sensitive in the two tails, but less sensitive in the central part, than Smirnov's test. 


\title{
PACIFIC JOURNAL OF MATHEMATICS
}

\author{
EDITORS
}

RalPh S. Phillips

Stanford University

Stanford, California

M. G. Arsove

University of Washington

Seattle 5 , Washington
A. L. Whiteman

University of Southern California Los Angeles 7, California

LOWell J. PAIGE

Unıversity of California

Los Angeles 24, California

\section{ASSOCIATE EDITORS}
E. F. BECKENBACH
D. DERRY
H. L. ROYDEN
E. G. STRAUS
T. M. CHERRY
M. OHTSUKA
E. SPANIER
F. WOLF

\section{SUPPORTING INSTITUTIONS}

\author{
UNIVERSITY OF BRITISH COLUMBIA \\ CALIFORNIA INSTITUTE OF TECHNOLOGY \\ UNIVERSITY OF CALIFORNIA \\ MONTANA STATE UNIVERSITY \\ UNIVERSITY OF NEVADA \\ NEW MEXICO STATE UNIVERSITY \\ OREGON STATE UNIVERSITY \\ UNIVERSITY OF OREGON \\ OSAKA UNIVERSITY \\ UNIVERSITY OF SOUTHERN CALIFORNIA
}

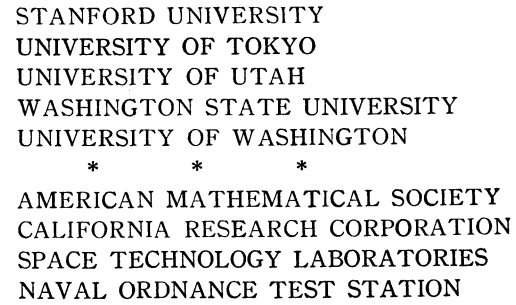

Mathematical papers intended for publication in the Pacific Journal of Mathematıcs should be typewritten (double spaced), and the author should keep a complete copy. Manuscripts may be sent to any one of the four editors. All other communications to the editors should be addressed to the managing editor, L. J. Paige at the University of California, Los Angeles 24, California.

50 reprints per author of each article are furnıshed free of charge; additional copies may be obtained at cost in multiples of 50 .

The Pacific Journal of Mathematics is published quarterly, in March, June, September, and December. Effective with Volume 13 the price per volume (4 numbers) is $\$ 18.00$; single issues, $\$ 5.00$. Special price for current issues to individual faculty members of supporting institutions and to individual members of the American Mathematical Society: $\$ 8.00$ per volume; single issues $\$ 2.50$. Back numbers are available.

Subscriptions, orders for back numbers, and changes of address should be sent to Pacific Journal of Mathematics, 103 Highland Boulevard, Berkeley 8, California.

Printed at Kokusai Bunken Insatsusha (International Academic Printing Co., Ltd.), No. 6 , 2-chome, Fujimi-cho, Chiyoda-ku, Tokyo, Japan.

PUBLISHED BY PACIFIC JOURNAL OF MATHEMATICS, A NON-PROFIT CORPORATION

The Supporting Institutions listed above contribute to the cost of publication of this Journal, but they are not owners or publishers and have no responsibility for its content or policies. 


\section{Pacific Journal of Mathematics}

\section{Vol. 12, No. $3 \quad$ March, 1962}

Alfred Aeppli, Some exact sequences in cohomology theory for Kähler

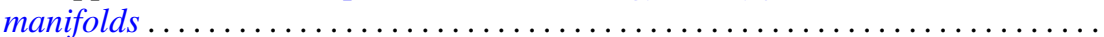

Paul Richard Beesack, On the Green's function of an N-point boundary value

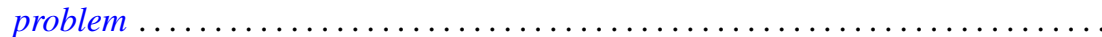

James Robert Boen, On p-automorphic p-groups....

James Robert Boen, Oscar S. Rothaus and John Griggs Thompson, Further results

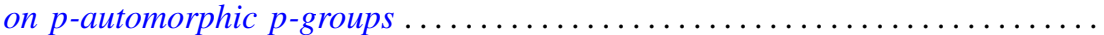

James Henry Bramble and Lawrence Edward Payne, Bounds in the Neumann problem for second order uniformly elliptic operators ..................

Chen Chung Chang and H. Jerome (Howard) Keisler, Applications of ultraproducts of pairs of cardinals to the theory of models .........................

Stephen Urban Chase, On direct sums and products of modules ................

Paul Civin, Annihilators in the second conjugate algebra of a group algebra .......

J. H. Curtiss, Polynomial interpolation in points equidistributed on the unit

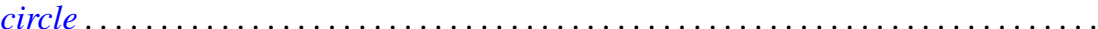

Marion K. Fort, Jr., Homogeneity of infinite products of manifolds with

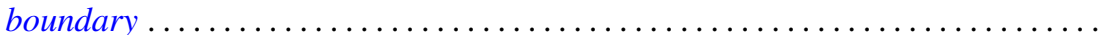

James G. Glimm, Families of induced representations . . . . . . . . . . . . . . .

Daniel E. Gorenstein, Reuben Sandler and William H. Mills, On almost-commuting

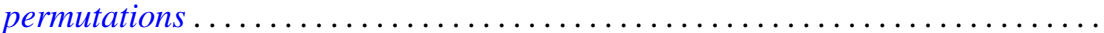

Vincent C. Harris and M. V. Subba Rao, Congruence properties of $\sigma_{r}(N) \ldots \ldots \ldots$

Harry Hochstadt, Fourier series with linearly dependent coefficients . . . . . . . . . . 925

Kenneth Myron Hoffman and John Wermer, A characterization of $C(X)$. .

Robert Weldon Hunt, The behavior of solutions of ordinary, self-adjoint differential equations of arbitrary even order...

Edward Takashi Kobayashi, A remark on the Nijenhuis tensor

David London, On the zeros of the solutions of $w^{\prime \prime}(z)+p(z) w(z)=0$

Gerald R. Mac Lane and Frank Beall Ryan, On the radial limits of Blaschke products...

T. M. MacRobert, Evaluation of an E-function when three of its upper parameters

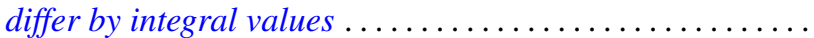

Robert W. McKelvey, The spectra of minimal self-adjoint extensions of a symmetric operator

Adegoke Olubummo, Operators of finite rank in a reflexive Banach space. .

David Alexander Pope, On the approximation of function spaces in the calculus of variations

Bernard W. Roos and Ward C. Sangren, Three spectral theorems for a pair of singular first-order differential equations...............

Arthur Argyle Sagle, Simple Malcev algebras over fields of characteristic zero .

S. C. Tang, Some theorems on the ratio of empirical distribution to the theoretical distribution

Robert Charles Thompson, Normal matrices and the normal basis in abelian number fields.

Howard Gregory Tucker, Absolute continuity of infinitely divisible distributions ... 